\title{
ANÁLISE QUÍMICA E SENSORIAL DE PLEUROTUS OSTREATUS CULTIVADO EM CASCA DE COCO SUPLEMENTADA COM FARELO DE TRIGO E/OU DE ARROZ
}

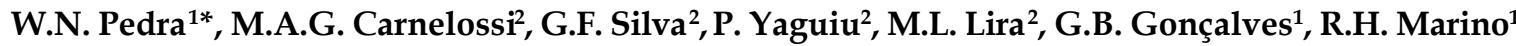

${ }^{1}$ Universidade Federal deSergipe, Departamento de Engenharia Agronômica, Av. Marechal Rondon, s/nํ,CEP 49100-000, São Cristóvão, SE, Brasil. E-mail: rehmarino@yahoo.com

\section{RESUMO}

\begin{abstract}
Foi realizado um ensaio com o cogumelo comestível (Pleurotus ostreatus) cultivado em casca de coco moída com suplementação de 0, 20 e 40\% de farelo de arroz e/ou de trigo. As amostras provenientes do cultivo foram congeladas, desidratadas e analisadas quanto à composição química e sensorial. O teor de proteína variou entre 8,33 e 19,98\%. O teor de cinzas ficou entre 5,5 e $9,7 \%$ e de lipídeos entre 0,23 e 4,4\%. Oteor médio de ferro foi de $15,53 \mathrm{mg} / 100$ ge deácido ascórbico variou entre 24,28 e 27,61 mg/100 g. A composição química foi influenciada pela suplementação e pelos isolados testados. A aceitação dos cogumelos quanto ao sabor e aparência foi influenciada pelo tipo de substrato e pelos isolados testados.
\end{abstract}

PALAVRAS-CHAVE: Pleurotus ostreatus, composição química, análise sensorial, pó de coco.

\section{ABSTRACT}

CHEMICAL AND SENSORIAL ANALYSIS OF PLEUROTUS OSTREATUS CULTIVATED ON COCONUT (COCOS NUCIFERA LINN.) HUSK SUPPLEMENTED WITH WHEAT AND/OR RICE BRAN. An assay on cultivated mushrooms (Pleurotus ostreatus) was carried out on coconut bark ground with 0,20 and $40 \%$ supplementation of rice and/or wheat bran. The samples obtained from the crops were frozen and dehydrated, and submitted to chemical and sensorial analysis. Protein levels ranged from 8.33 to $19.98 \%$. Ashes ranged from 5.5 to $9.7 \%$ and lipid content was 0.23 to $4.4 \%$. The average iron content was $15.53 \mathrm{mg} / 100 \mathrm{~g}$, and ascorbic acid ranged from 24.28 to $27.61 \mathrm{mg} /$ $100 \mathrm{~g}$. The chemical composition was influenced by the supplementation and by the isolates tested. The acceptance of the mushrooms in regard to flavor and appearance was influenced by the type of substratum and the isolates tested.

KEY WORDS: Pleurotus ostreatus, chemical composition, sensorial analysis, coconut bark.

\section{INTRODUÇÃO}

Os cogumelos atualmente são considerados como alimentos nutracêuticos ou funcionais fisiológicos (Bonatti et al.,2004; CheunG; Cheung, 2005; Furlani; Godor, 2005).

São conhecidas cerca de 2.000 espécies de cogumelos comestíveis, mas apenas 25 delas são comercialmente cultivadas. No Brasil, as principais espécies comestíveis cultivadas sãoAgaricus bisporus, Lentinula edodes e Pleurotus spp. e, recentemente, a espécies $A$. blazei tem despertado interesse (FurLani; Godor, 2005).

Cogumelos do gênero Pleurotus, comumente conhecido como cogumelo ostra, desenvolvem-se em florestas tropicais e subtropicais e podem ser cultiva- dos em meios artificiais. Este cogumelo apresenta elevado teor de proteínas, carboidratos, minerais (cálcio, fósforo e ferro) e vitaminas (tiamina, riboflavina e niacina), assim como baixo teor de gorduras (JusTOet al., 1998; MANZI et al., 1999; SHASHIREKHA et al., 2005; Toro et al., 2006).

O cogumelo do gêneroPleurotus tem sido estudado intensivamente em muitas partes do mundo pelo seu valor gastronômico, habilidade em colonizar e degradar uma grande variedade de resíduos lignocelulósicos, por apresentar ciclo relativamente curto em comparação com outros gêneros de cogumelos comestíveis e também por ser possível o seu cultivo em ambiente rústico de produção (BONATTiet al.,2004; EIRA, 2004; PEDRA; MARINO, 2006).

\footnotetext{
${ }^{2}$ UniversidadeFederal deSergipe, Departamento de Engenharia Química, Laboratório de Tecnologia de Alimentos, São Cristóvão, SE, Brasil.

*Bolsista PIBIC/UFS/COPES.
} 
No Estado deSergipe há uma grande produção de coco (Cocos nucifera Linn.), sendo que a casca ou pó de coco tem sido empregada, principalmente, na produção de mudas de espécies arbóreas e florestais.

O objetivo deste trabalho foi avaliar o efeito da suplementação da serragem da casca de coco com farelos de trigo e/ou de arroz na composição química e na aceitação (análise sensorial) dos basidiomas de Pleurotus spp. produzidos que, futuramente, poderão ser comercializados na região Nordeste do país. É importante ressaltar que não foram encontrados relatos sobre o efeito da utilização da casca de coco verde moída na composição química e sensorial de cogumelos comestíveis.

\section{MATERIAL E MÉTODOS}

A produção dos basidiomas foi realizada na Clínica Fitossanitária e no Horto Florestal; as análises químicas e sensoriais foram realizadas no Laboratório de Tecnologia de Alimentos do Departamento de Engenharia Química da Universidade Federal de Sergipe (UFS), Brasil.

\section{Origem dos isolados}

Os isolados DF50 e POS04 de Pleurotus ostreatus foram obtidos por doação da Micoteca do Módulo de Cogumelos Comestíveis da Faculdade de Ciências Agronômicas, Botucatu, SP.

\section{Produção dos basidiomas}

O substrato à base de casca de coco moída foi suplementado com 0, 20 e $40 \%$ de farelo de arroze/ou de trigo (Tabela 1) e preparado conforme metodologia descrita por PEDRA; MARINO (2006).

O volume de substrato foi padronizado em $200 \mathrm{~g}$ da mistura e acondicionado em frascos de $500 \mathrm{~mL}$ vedado com tampas furadas no centro, preenchido com tampão de algodão e autoclavado por 40 minutos por duas vezes, com intervalo de 24 horas, à 1 atm e $120^{\circ} \mathrm{C}$.

Após o resfriamento do substrato, foi realizada a inoculação, em condições assépticas (câmara de fluxo laminar), pela transferência de um disco de $6 \mathrm{~mm}$ de diâmetro proveniente das matrizes multiplicadas em meio de cultura batata-dextrose-água (BDA). A incubação foi à temperatura de $25 \pm 3^{\circ} \mathrm{C}$ por 30 dias. Foram realizadas quatro repetições por isolado.

Para a análise sensorial foi utilizado o substrato à base de serragem de Maçaranduba (Manilkara spp.) suplementado com farelo, segundo os mesmos tratamentos utilizados para casca de coco (Tabela 1), como controle para as avaliações química e sensorial.
Tabela 1 - Suplementação do substrato à base de casca de coco verde moída.

\begin{tabular}{crcc}
\hline Tratamento & SCC $^{1}$ & Farelo de arroz & Farelo de trigo \\
\hline T1 & $100 \%$ & $0 \%$ & $0 \%$ \\
T2 & $80 \%$ & $20 \%$ & $0 \%$ \\
T3 & $80 \%$ & $0 \%$ & $20 \%$ \\
T4 & $60 \%$ & $20 \%$ & $20 \%$ \\
T5 & $60 \%$ & $40 \%$ & $0 \%$ \\
T6 & $60 \%$ & $0 \%$ & $40 \%$ \\
\hline
\end{tabular}

${ }^{1}$ Casca de coco verde lavada submetida ao processo de compostagem e moída (dados do fornecedor).

Após a colonização, os frascos foram submetidos à hidratação e ao choque térmico. Para tanto, retirouse a tampa dos frascos e foi acrescentada uma lâmina d'água e os frascos foram acondicionados em refrigerador durante 4 horas (EIRA; MINHONI, 1997). Emsegui$\mathrm{da}$, os frascos foram transferidos para o ambiente rústico de frutificação, no Horto Florestal da Universidade Federal de Sergipe.

\section{Composição química}

Os cogumelos produzidos em casca de coco moída foram submetidos a dois tratamentos de conservação: congelamento e desidratação à temperatura de $60^{\circ} \mathrm{C}$ por 24 horas.

O teor de nitrogênio foi determinado pelo método Kjeldahl. A proteína bruta do cogumelo foi determinada através do teor de nitrogênio utilizando-se o fator de conversão $\mathrm{N}$ x 4,38 (SHASHIREKHA et al., 2002). Os teores de cinzas e de vitamina C (ácido ascórbico) foram determinados pela metodologia descrita pela Association of Official de Analytical Chemists (AOAC, 1990). O teor de ferroe delipídios foi determinado pela metodologia de LARA et al. (1976).

\section{Análise sensorial}

As amostras foram submetidas à análise por 30 provadores não treinados, em 10 sessões. As análises foram realizadas, sob iluminação natural, para avaliar a aparência visual e o sabor do produto. A cada provador foram oferecidas amostras de $5 \mathrm{~g}$ de cogumelos desidratados, sem nenhum tratamento, duas escalas hedônicas (sabor eaparência) e uma escala de atitude (Figs. 1 e 2).

\section{Análise estatística}

Os resultados das análises químicas e sensoriais foram submetidos à Análise de Variância (ANOVA) e aplicado o Teste de Tukey em nível de 5\% de significância para comparação das médias. 
Nome:.................................. Data:..........

Por favor, avalie a amostra utilizando as escalas abaixo para escrever o quanto você gostou ou desgostou do produto, em relação ao SABOR e à APARÊNCIA. Marque em cada escala, a posição que melhor reflita seu julgamento.

SABOR:

APARÊNCIA:
(9) Gostei
(9) Gostei extremamente
(8) Gostei muito
(8) Gostei muito
(7) Gostei moderadamente
(7) Gostei moderadamente
(6) Gostei ligeiramente
(6) Gostei ligeiramente
(5) Indiferente
(5) Indiferente
(4) Desgostei ligeiramente
(4) Desgostei ligeiramente
(3) Desgostei moderadamente
(3) Desgostei moderadamente
(2) Desgostei muito
(1) Desgostei extremamente
(2) Desgostei muito
(1) Desgostei extremamente

Fig. 1 - Escala hedônica

Nome:

Data.

Por favor, prove a amostra servida e marque a resposta que melhor corresponde ao seu julgamento:

(9) Comeria isto sempre que tivesse oportunidade

(8) Comeria isto muito freqüentemente

(7) Comeria isto freqüentemente

(6) Gosto disso e comeria de vez em quando

(5) Comeria se estivesse acessível, mas não me esforçaria para isso

(4) Não gosto disso, mas comeria ocasionalmente

(3) Taramente comeria isto

(2) Só comeria se não pudesse escolher outro alimento

(1) Só comeria isso se fosse forçado

Fig. 2 - Escala de atitude

\section{RESULTADOS E DISCUSSÃO}

\section{Basidiomas congelados}

A composição química dos basidiomas dos isolados do cogumelo comestível P. ostreatus, cultivados em substrato casca de coco moída e conservados por congelados, é mostradas na Tabela 2.

Poucos trabalhos analisaram o teor de vitamina $C$ em cogumelos e, somente nos últimos anos, como também citado porFuRLANI; Godor (2005), éque dados analíticos estão disponíveis na literatura internacional. Neste experimento, o teor de vitamina C não diferiu entre os isolados testados, mas houve variação com o nível de suplementação da casca de coco verde moída (Tabela 2; Fig. 3). O valor médio de vitamina C foi 25,95 mg/100 g deácido ascórbico, em baseúmida. Batista-Justo et al. (1998) citaram que isolados de $P$. ostreatus originários do México apresentaram, em média, de 28 a 35 mg/100 g de ácido ascórbico, em base seca. Já RIos-HuRTADo et al. (2003) analisaram $P$. sajor-caju cultivados em diferentes substratos orgânicose obtiveram valores de vitamina C de1,19a 194,14. Estes valores estão expressos em mg/100 g de parte comestível e não foi especificado se os resultados são em base seca ou úmida.

Tabela 2 - Composição química ${ }^{1}$ média dos basidiomas congelados de $P$. ostreatus cultivados em casca de coco moída suplementada com farelos.

\begin{tabular}{lccccc}
\hline Isolado & Vit. C & Cinzas & Proteína & Lipídeo & Ferro \\
\hline DF 50 & $27,61 \mathrm{a}^{2}$ & $7,66 \mathrm{a}$ & $11,05 \mathrm{~b}$ & $1,26 \mathrm{~b}$ & $13,75 \mathrm{~b}$ \\
POS 04 & $24,28 \mathrm{a}$ & $6,55 \mathrm{~b}$ & $13,89 \mathrm{a}$ & $2,25 \mathrm{a}$ & $17,30 \mathrm{a}$ \\
\hline
\end{tabular}

${ }^{1}$ Vit.C e Ferro dados em mg/100 g de amostra; Cinzas, Proteína, Lipídeo em \%;

${ }^{2}$ Valores com letras iguais, na mesma coluna, não diferem significativamente entre si a $5 \%$ de probabilidade. 
Neste experimento, a concentração de cinzas ficou entre 5,5 a 9,7\%, cujo valor médio ficou em 6,9\% (Tabela 2) e próximo ao encontrado por STURION; Oetterer (1995) eBAniK; NANDi (2004) com ocultivo de Pleurotus spp. em diferentes substratos.

Considerando o teor de proteínas, têm-se os valores entre 8,33 a 19,98\%, sendo que o isolado POS 04 apresentou maior concentração protéica em comparação com DF50 (Tabela 2). O valor médio do teor protéico foi de $12,47 \%$ e são considerados próximos ao observado por AKINDAHUNSI; OVETAYO (2006) com isolado de Pleurotus tuber-regium. Já BonAtTi et al. (2004) citaram que, para diferentes espécies dePleurotus cultivados em resíduos de bananeira e de arroz, o teor protéico variou de 1,54 a 3,10\% (base úmida), similar ou maior que o teor de proteína encontrado em muitos tipos de vegetais. Neste experimento, o teor de proteínas ficou próximo do citado por BonATTIet al.(2004) para ovos de galinhas $(12,30 \%)$ e menor que aqueles encontrados em queijos (18\%). Por outro lado, MANZI et al. (1999) citaram que diferentes isolados de $P$. ostreatus apresentaram teor de proteínas entre 19,93 a $34,73 \%$, em base seca ou 1,18 e 4,92\% (base úmida). Nesse mesmo trabalho também foram determinados os teores de proteína em outras espécies, como o $P$. eryngii, $P$. pulmonarius e os valores obtidos foram de 22,74 a $30,48 \%$ (base seca).

A comparação entre as espécies mostrou que houve uma grande variabilidade dos teores de proteína que, segundoFurLANi;Godor (2005), pode ser explicada pela concentração de quitina presente em cada espécie. Os cogumelos possuem uma significativa quantidade de compostos nitrogenados não protéicos, na forma de quitina, em suas paredes celulares e tais compostos não são digeríveis. Para não superestimar o conteúdo protéico de cogumelos, o fator 4,38 é adotado, pois esse valor assume que apenas $70 \%$ dos compostos nitrogenados existentes no cogumelo sejam digeríveis pelo organismo humano (CRISAN;S ANDS, 1978; Bano; Rarajaratham, 1988; Sturion; Oetterer, 1995; FuRLANI; GODOY, 2005).

Dentre os muitos fatores que podem influenciar o valor protéico dos cogumelos talvez o mais importante seja o substrato (FURLANI; GODOY, 2005).

WANG et al. (2001) eSturion; Oetterer (1995) mencionam que o teor de proteína bruta dos corpos de frutificação parece estar relacionado com o teor de nitrogênio no substrato inicial.

Neste trabalho, a suplementação com fontes nitrogenadas influenciou a concentração de proteínas nos cogumelos produzidos em SCC, nos dois isolados testados (Fig. 3).

Considerando-se o isolado DF50, tem-se que a suplementação com $40 \%$ de farelo de arroz resultou em maior concentração de proteínas do que quando se utilizou $40 \%$ de farelo de trigo. Enquanto que, para
POS04, o nível protéico máximo foi atingido com $20 \%$ de farelo de trigo e que o aumento da suplementação reduziu a concentração de proteínas (Fig. 3).

WANG et al. (2001) citaram que a suplementação com farelo de trigo teve um grande potencial para melhorar a acumulação de proteínas no $P$. ostreatusdo que quando se utilizou o farelo de arroz ou farelo de milho. A partir dos resultados obtidos neste experimento, tem-se que os teores de proteína variam com o tipo de substrato, espécie e material utilizado na suplementação do substrato, como observado por Mendez et al. (2005).

Outro fator a ser considerado, segundo FurLANI; Godor (2005), é o estádio de desenvolvimento. Segundo EKANEM; UBENGAMA (2002), o estádio de maturação (botão e totalmente desenvolvido) em amostras de $P$. ostreatus influencia significativamente o teor de proteína, pois no cogumelo ainda botão o valor foi de $28 \%$ e para o totalmente desenvolvido foi de $40,25 \%$ (base seca) de proteínas. Neste experimento, os cogumelos foram coletados totalmente desenvolvidos e não foi realizada avaliação entre os estádios de desenvolvimento.

O teor de lipídeos ficou entre 0,23 e 4,41\%, com valor médio de $1,74 \%$, com diferença significativa entre os isolados testados (Tabela 2). Toro et al.(2006) mencionam que espécies de Pleurotus spp. apresentaram, em média, teor de lipídios entre 4,58 e 5,19\%. StURION;OETtERER (1995) citaram a presença de 2,85\% de lipídeos nos basidiocarpos de Pleurotus spp., cultivados em diferentes substratos. BANO; RAJARATHNAM (1988) citaram que, em média, as diferentes espécies do cogumelo Pleurotus apresentaram teores delipídeos entre 2 e $8 \%$ (base seca).

Do mesmo modo, como foi observado na concentração de proteínas, o teor de lipídeos foi influenciado com o aumento da suplementação. O isolado DF50 apresentou maior concentração com $40 \%$ de farelo de arroz ou de trigo. Enquanto que, para POS04, a concentração máxima foi observada nos tratamentos com 20 e $40 \%$ de farelo trigo (Fig. 3).

A concentração média de ferro foi de $15,53 \mathrm{mg} /$ $100 \mathrm{~g}$ de massa úmida com diferença significativa entre os isolados testados (Tabela 2).STURION;OETTERER (1995) citaram que o cultivo de Pleurotus spp., em diferentes resíduos agrícolas resultou em basidiocarpos com teores de ferro entre 8,2 a 17,5 $\mathrm{mg} / 100 \mathrm{~g}$ de amostra seca. Estes autores mencionam uma variação significativa na composição química e no teor de minerais em função da variação do tipo de substrato, tal como ocorreu neste trabalho, com a suplementação do substrato SCC com farelo de arroz e/ ou de trigo (Fig. 3).

Desta forma, tem-se que a suplementação influenciou a composição química dos isolados de Pleurotus ostreatus cultivados em serragem da casca de coco. 


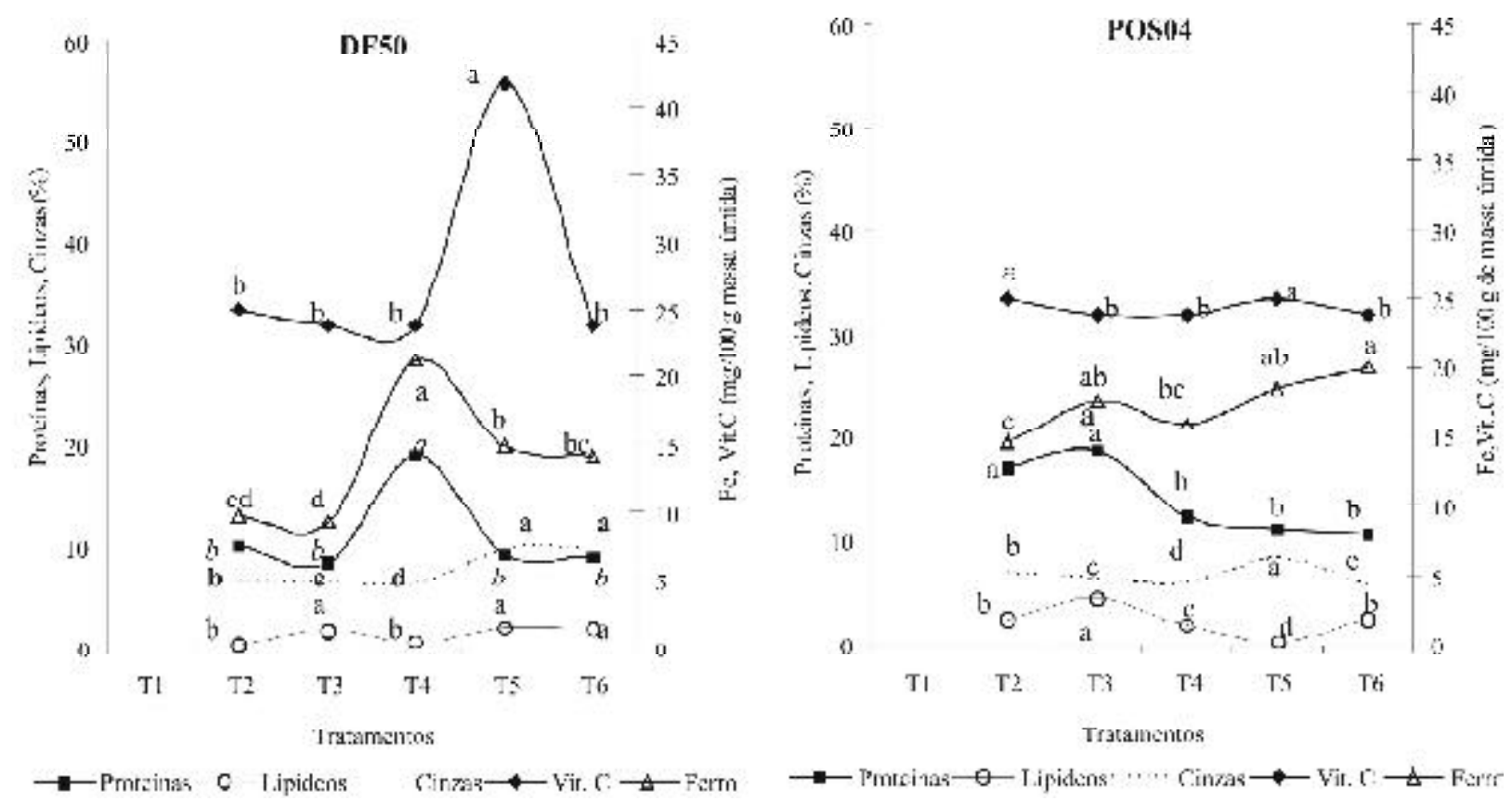

Fig. 3 - Composição química média dos basidiomas dos cogumelos P. ostreatus congelados produzidos em casca de coco moída suplementada com farelos ${ }^{1,2}$.

${ }^{1}$ Tratamentos: T1 - controle; T2 - 20\% de farelo de trigo; T3 - 20\% de farelo de arroz; T4 - 20\% de farelo de arroz e $20 \%$ de farelo de trigo; T5 - 40\% de farelo de trigo e T6 - 40\% de farelo de arroz;

${ }^{2}$ Valores com letras iguais, na mesma linha (letra minúscula), não diferem significativamente entre si a $5 \%$ de probabilidade.

\section{Cogumelos desidratados}

As composições químicas dos basidiomas dos isolados $P$. ostreatus cultivados em SM e SCC e conservados desidratados são mostrados nas Tabelas 3 a 5 .

MANZI et al.(2001) enfatizaram que a composição química dos basidiocarpos de Agaricus bisporus, P. ostreatuse Boletus spp. sofreualterações entre os diferentes métodos de processamento. Neste trabalho, observa-se que a desidratação influenciou na composição química dos cogumelos $P$. ostreatus, reduzindo o teor de lipídeos e cinzas e aumentando o de ferro e de proteínas (comparar as Tabelas 2 e 3$)$.

MANZi et al.(1999) também mencionaram que o teor de proteínas varia de acordo com a espécie de cogumelo cultivado. Estes autores citam que o cultivo de $P$. ostreatus eP.pulmonarius em palha de trigo apresentou 19,93 a 34,73\% e 30,48\% (base seca), respectivamente, de proteínas. Da mesma forma, MAZIERO (1990) citou que os basidiocarpos de P. ostreatus produzidos em folha de bananeira apresentaram cerca de $20 \%$ de proteína bruta, similar ao valor encontrado porGUPTA et al. (1982).

Sturion; Oetterer (1995) citam que o teor de proteína bruta variou de 17,38 a $25,51 \%$ dependendo da espécie de Pleurotus e do tipo de substrato utilizado no cultivo. Por outro lado, Yildiz et al. (1998) citaram que o cultivo de $P$. ostreatusem serragem de amendoim e palha de trigo apresentou cogumelos com 34,6 e $23,5 \%$ de proteínas (base seca).

Tal como observado anteriormente, o teor de proteína bruta dos basidiomas de cogumelos comestíveis vem sendo relacionado com o teor de nitrogênio presente no substrato (Yildiz et al., 1998; FURLANI;GodoY, 2005). Por sua vez, WANG et al. (2001) mencionaram que o teor de proteína de $P$. ostreatus em palha suplementado com palha de arroz foi de $41,5 \%$ e palha suplementada com farelo de trigo o teor protéico ficou entre 46,3 e $53,3 \%$.

No Brasil, o cultivo do cogumelo P. ostreatus pelo sistema axênico (substrato autoclavado), utilizandose serragem de Eucalyptus spp. suplementado com farelos, vem sendo bastante difundido nos últimos tempos (EIRA, 2004). A utilização de serragem da casca de coco suplementada com farelos de arroz e/ou de trigo resultou em cogumelos com teores protéicos entre 38,58 e $41,36 \%$ dependendo do isolado (Tabelas 4 e 5).

De acordo comSturion; OetTerer (1995) eMendez et al. (2005), o valor nutricional dos cogumelos pode ser afetado pelo substrato de cultivo, tal como observado neste trabalho com os isolados testados cultivados em SCC e SM (Tabelas 4 e 5). 
Tabela 3 - Composição química ${ }^{1}$ média dos basidiomas de $P$. ostreatus cultivados em casca de coco moída e serragem de Massaranduba spp. suplementados com farelos e desidratados.

\begin{tabular}{llccc}
\hline Isolado & Cinzas & Proteína & Lipídeos & Ferro \\
\hline DF 50 & $6,06 \mathrm{~b}^{2}$ & $38,44 \mathrm{a}$ & $0,75 \mathrm{~b}$ & $21,17 \mathrm{a}$ \\
POS 04 & $6,47 \mathrm{a}$ & $37,89 \mathrm{a}$ & $1,79 \mathrm{a}$ & $20,16 \mathrm{~b}$ \\
\hline
\end{tabular}

${ }^{1}$ Ferro: dados em mg/100 g de amostra; Cinzas, Proteína, Lipídeo em: \%;

${ }^{2}$ Valores com letras iguais, numa mesma coluna, não diferem significativamente entre si a 5\% de probabilidade.

Tabela 4 - Composição química ${ }^{1}$ dos basidiomas do isolado DF50 de P. ostreatus desidratados e cultivados em casca de coco moída e serragem de Massaranduba spp. suplementados com farelos.

\begin{tabular}{llccc}
\hline Substrato & Cinzas & Proteínas & Lipídeos & Ferro \\
\hline Serragem de Massaranduba & $5,81 \mathrm{~b}^{2}$ & $35,53 \mathrm{~b}$ & $0,71 \mathrm{a}$ & $21,11 \mathrm{a}$ \\
Casca de coco & $6,31 \mathrm{a}$ & $41,36 \mathrm{a}$ & $0,79 \mathrm{a}$ & $21,22 \mathrm{a}$ \\
\hline
\end{tabular}

${ }^{1}$ Ferro: dados em mg/100 g de amostra; Cinzas, Proteína, Lipídeo em: \%;

${ }^{2}$ Valores com letras iguais, numa mesma coluna, não diferem significativamente entre si a 5\% de probabilidade.

Tabela 5 - Composição química ${ }^{1}$ dos basidiomas do isolado POS 04 de P. ostreatus desidratados e cultivados em casca de coco moída e serragem de Massaranduba spp. suplementados com farelos.

\begin{tabular}{lllll}
\hline Substrato & Cinzas & Proteínas & Lipídeos & Ferro \\
\hline Serragem de Massaranduba & $5,40 \mathrm{~b}^{2}$ & $37,19 \mathrm{a}$ & $1,91 \mathrm{a}$ & $20,99 \mathrm{a}$ \\
Casca de coco & $7,54 \mathrm{a}$ & $38,58 \mathrm{a}$ & $1,68 \mathrm{a}$ & $19,33 \mathrm{~b}$ \\
\hline
\end{tabular}

${ }^{1}$ Ferro: dados em mg/100 g de amostra; Cinzas, Proteína, Lipídeo em: \%;

${ }^{2}$ Valores com letras iguais, numa mesma coluna, não diferem significativamente entre si a $5 \%$ de probabilidade.

Outro fator importante a ser ressaltadoé o aumento do teor protéico do substrato após o cultivo de Pleurotus, como relatado por WANG et al. (2001). Estes autores relacionam este comportamento à atividade metabólica do micélio em crescimento e da decomposição do substrato em gás carbônico eágua (ZADRAZIL; Dube, 1992).

Este aumento de proteínas após o cultivo de cogumelos poderepresentar um métodoalternativo de produção de ração animal a baixo custo para os pequenos produtores. No entanto, são necessários mais estudos para a viabilização da utilização da serragem ou da fibra da casca do coco na alimentação animal.

Em termos de teor de lipídeos observa-se uma redução quando submetido à desidratação (Tabelas 2 e 3). Isto deve ter sido devido à degradação das gorduras dos cogumelos quando submetidos ao aquecimento a $60^{\circ} \mathrm{C}$, por 24 horas.

O teor de ferro ficou entre 19,33 e 22,33 mg / $100 \mathrm{~g}$ de amostra (Tabelas 3 a 5), próximos aos obtidos por Sturion; Oetterer (1995), os quais citaram que o cultivo de isolados de Pleurotus spp. em resíduos à base de palha de bananeira, palha de trigoe/ ou sabugo de milho apresentou teores entre 2,7 e 56,1 mg/100 g de substrato, com maior concentração nos isolados de $P$. ostreatoroseus. De acordo com BANO; RARAJATHNAM (1988), embora seja encontrado em baixa concentração, este elemento está na forma disponível, prontamente utilizável pelos microrganismos.

Tal como relatado por FuRLANI; GODOY (2005), apesar da existência da diferença de composição, dependendo das espécies e dos substratos de cultivo utilizados para produção de cogumelos comestíveis, estes podem ser considerados excelentes alimentos devido às características nutricionais, principalmente, pelo elevador teor de proteínas e baixos teores de gorduras, resultando em um alimento de baixo teor calórico, importante em uma dieta balanceada.

\section{Análise sensorial}

Na análise sensorial dos isolados de $P$. ostreatus, na escala de atitude, tem-se que na média o consumo deste cogumelo na região seria raro, provavelmente, por uma questão de costume regional em não consumir esse tipo dealimento. Além disso, a utilização dos substratos SCC e SM não influenciaram neste parâmetro, nos isolados testados (Tabela 6). 
Tabela 6 - Média das notas ${ }^{1}$ da avaliação sensorial da aceitação (escala de atitude ${ }^{1}$ ) dos cogumelos $P$. ostreatus cultivados em casca de coco moída e serragem de Maçaranduba (Manilkara spp.) suplementados.

\begin{tabular}{lll}
\hline Substratos/Isolados & DF 50 & POS 04 \\
\hline Serragem de Maçaranduba & $3,46 \mathrm{a}, \mathrm{A}^{2}$ & $3,40 \mathrm{a}, \mathrm{A}$ \\
Casca de coco & 2,90 a, A & 2,67 a, A \\
\hline
\end{tabular}

${ }^{1}$ Notas: (9) Comeria isto sempre que tivesse oportunidade; (8) Comeria isto muito freqüentemente; (7) Comeria isto freqüentemente; (6) Gosto disso e comeria de vez em quando; (5) Comeria se estivesse acessível, mas não me esforçaria para isso; (4) Não gosto disso, mas comeria ocasionalmente; (3) raramente comeria isto; (2) Só comeria se não pudesse escolher outro alimento e (1) Só comeria isso se fosse forçado.

${ }^{2}$ Valores com letras iguais, numa mesma coluna (letra minúscula) ou numa mesma linha (letra maiúscula), não diferem significativamente entre sia $5 \%$ de probabilidade.

Tabela 7 - Média das notas ${ }^{1}$ da análise sensorial do sabor (escala hedônica ${ }^{1}$ ) dos cogumelos P. ostreatus cultivados em casca de coco moída e serragem de Maçaranduba (Manilkara spp.) suplementados.

\begin{tabular}{lll}
\hline Substratos/Isolados & DF 50 & POS 04 \\
\hline Serragem de Maçaranduba & $4,70 \mathrm{a}, \mathrm{A}^{2}$ & $4,53 \mathrm{a}, \mathrm{A}$ \\
Casca de coco & 3,93 a, A & $3,53 \mathrm{~b}, \mathrm{~A}$ \\
\hline
\end{tabular}

${ }^{1}$ Notas: (9) Gostei extremamente, (8) Gostei muito, (7) Gostei moderadamente, (6) Gostei ligeiramente, (5) Indiferente, (4) Desgostei ligeiramente, (3) Desgostei moderadamente, (2) Desgostei muito e (1) Desgostei extremamente;

${ }^{2}$ Valores com letras iguais, numa mesma coluna (letra minúscula) ou numa mesma linha (letra maiúscula), não diferem significativamente entre sia $5 \%$ de probabilidade.

Tabela 8 - Média das notas ${ }^{1}$ da análise sensorial da aparência (escala hedônica ${ }^{1}$ ) dos cogumelos P. ostreatus cultivados em casca de coco moída e serragem de Maçaranduba (Manilkara spp.) suplementados.

\begin{tabular}{lcc}
\hline Substratos/Isolados & DF 50 & POS 04 \\
\hline Serragem de Maçaranduba & $5,00 \mathrm{a}, \mathrm{A}^{2}$ & $4,90 \mathrm{a}, \mathrm{A}$ \\
Casca de coco & $4,50 \mathrm{a}, \mathrm{A}$ & $3,63 \mathrm{~b}, \mathrm{~B}$ \\
\hline
\end{tabular}

${ }^{1}$ Notas: (9) Gostei extremamente, (8) Gostei muito, (7) Gostei moderadamente, (6) Gostei ligeiramente, (5) Indiferente, (4) Desgostei ligeiramente, (3) Desgostei moderadamente, (2) Desgostei muito e (1) Desgostei extremamente.

${ }^{2}$ Valores com letras iguais, numa mesma coluna (letra minúscula) ou numa mesma linha (letra maiúscula), não diferem significativamente entre sia $5 \%$ de probabilidade.
Por outro lado, considerando a aceitação quanto ao sabor e aparência, observa-se que a utilização do substrato SCC reduziu significativamente este parâmetro em comparação ao substrato SM, apenas no isolado POS 04 (Tabelas 7 e 8).

Outrofator que pode ter influenciadoa aceitação do P. ostreatus, pode ter sido a forma como foram apresentados. A desidratação altera a textura do cogumelo e a ausência de tratamentos, como adição de sal, pode ter afetado a aceitação, além do fato que na região não se tem o hábito de se consumir este tipo de alimento.

\section{CONCLUSÕES}

Com base na metodologia empregada e nos resultados obtidos, conclui-se que:

- a composição química dos cogumelos foi influenciada pela desidratação, pelo tipo de substrato e pelos isolados de P. ostreatus;

- o tipo de substrato de cultivo do P. ostreatus influenciou no sabor e na aceitação deste cogumelo.

\section{AGRADECIMENTOS}

Os autores agradecem à Fundação de Amparo de Pesquisa do Estado de Sergipe (FAP-SE), à Universidade Federal de Sergipe e ao Conselho Nacional de Desenvolvimento Tecnológico e Científico (CNPq) pelo financiamento e pelas bolsas de estudos.

\section{REFERÊNCIAS}

AKINDAHUNSI, A.A.; OVETAYO, F.L. Nutrient and antinutrient distribution of edible mushroom, Pleurotus tuber-regium (Fries) Singer. Food Science and Technology, v.39, n.5, p.548-553, 2006.

ASSOCIATION OF OFFICIAL ANALYTICAL CHEMISTS. Official methods of analysis. Washington: AOAC, 1990. v.1.

BANIK, S.; NANDI, R. Effect of supplementation of rice straw with biogas residual slurry manure on the yield, protein and mineral contents of oyster mushroom. Industrial Crops and Products, v.20, p.311-319, 2004.

BANO, Z.; RAJARATHNAM, S. Pleurotus mushrooms: Part II. Chemical composition, nutritional value, postharvest physiology, preservation, and role as human food. Critical Review Science Nutrient, v.27, p.147-158, 1988.

BATISTA-JUSTO, M.B.; GUZMÁN, G.A.; MEJÍA, E.G.; DÍAZ, C.L.G.; MARTÍNEZ, G.; CORONA, E.B.

Composition química de tres cepas mexicanas de setas (Pleurotus ostreatus). Archivos Latinoamericanos de Nutricion, v.48, n.4, p.359-363, 1998. 
BONATTI, M.; KARNOPP, P.; SOARES, H.M.; FURLAN, S.A. Evaluation of Pleurotus ostreatus and Pleurotus sajor-caju nutritional characteristics when cultivated in different lignocellulosic wastes. Food Chemistry, v.88, p.425-428, 2004.

CHEUNG, L.M.; CHEUNG, P.C.K. Mushroom extracts with antioxidant activity against lipid peroxidation. Food Chemistry, v.89, p.403-409, 2005.

CRISAN, E.V.; SANDS, A. Nutritional value. In: CHANG, S.; HAYES, W.S. (Ed.). The biology and cultivation of edible mushrooms. New York: Academic Press, 1978. p.137-168.

EIRA, A.F.; MINHONI, M.T.A. Manual teórico-prático do cultivo de cogumelos comestíveis. Botucatu: Fundação de Pesquisa Agropecuária e Florestais, 1997. 75p.

EIRA, A.F. Fungos comestíveis. In: ESPÓSITO, E.; AZEVEDO, J.L. (Ed.). Fungos: uma introdução à biologia, bioquímica e biotecnologia. Caxias do Sul: Educs, 2004. 510p.

EKANEM E.O; UBENGAMA, V.S. Chemical composition, anti-nutritional factors and shelf life of oyster mushroom (Pleurotus ostreatus). Journal of Food Science and Technology, v.39, n.6, p.635-638, 2002.

FURLANI, R.P.Z.; GODOY, H.T. Valor nutricional de cogumelos comestíveis: uma revisão. Revista do Instituto Adolfo Lutz, v.64, n.2, p.149-154, 2005.

GUPTA, S.; MISRA, P.S.; PATHAK, M.C.; SING, M.S. Cultivation and nutritive value of pink mushroom. Fitoterapia, v.53, p.57-61, 1982.

JUSTO, M.B.; GUZMÁN, G.A.; MEJÍA, E.G.; DÍAZ, C.L.G.; MARTÍNEZ, G.; CORONA, E.B. Composition química de tres cepas mexicanas de setas (Pleurotus ostreatus). Archivos Latinoamericanos de Nutricion, v.48, n.4, p.359-363, 1998.

LARA, A.B.W.; NOZÁRIO, G.; ALMEIDA, M.E.W.; PREGNOLATO, W. Normas analíticas do Instituto Adolfo Lutz - Métodos químicos e físicos para análise de alimentos. São Paulo: Instituto Adolfo Lutz, 1976. v.1, p.165-178.

MARINO, R.H.; EIRA, A.F.; CARDOSO, E.Q. Melhoramento genético de Pleurotus ostreatus (Jacq.: Fr.) Kumm. por cruzamentos multispóricos visando a obtenção de isolados resistentes ao calor. Hoehnea, v.33, n.3, p.349-357, 2006.

MANZI, P.; GAMBELLI, L.; MARCONI, S.; VIVANTI, V.; PIZZOFERRATO, L. Nutrients in edible mushrooms: an inter-species comparative study. Food Chemistry, v.65, p.477-482, 1999.

MANZI, P.; AGUZZI, A.; PIZZOFERATO, L.

Nutritional value of mushrooms widely consumed in Italy. Food Chemistry, v.73, p.321-325, 2001.

MAZIERO, R. Substratos alternativos para o cultivo de Pleurotus spp. 1990. 136p. Dissertação (Mestrado em
Ciências Biológicas) - Instituto de Biociências, Universidade de São Paulo, São Paulo, 1990.

MENDEZ, L.A.; CASTRO, C.A.S.; CASSO, R.B.; LEAL, C,M.C. Effect of substrate and harvest on the amino acid profile of oyster mushroom (Pleurotus ostreatus). Journal of Food Composition and Analysis, v.18, p.447-450, 2005.

PEDRA, W.N.; MARINO, R.H. Cultivo Axênico de Pleurotus spp. em serragem da casca de coco (Cocos nucifera Linn.) suplementada com farelo de arroz e/ou trigo. Arquivos do Instituto Biológico, São Paulo, v.73, n.2, p.219-225, 2006.

RIOS-HURTADO, A.; TORRES-TORRES, G.; MEDINARIVAS, M.A. Caracterización bromatológica de la seta (Pleurotus sajor-caju) producida em cuatro sustratos orgánicos. Alimentaria, n.349, p.85-89, 2003.

SHASHIEREKHA, M.N.; RAJATHNAM, S.; BANO, Z. Enhancement of bioconversion efficiency and chemistry of mushroom P. sajor caju (Berk \& Br.) Sacc. Produced on spent rice straw substrate supplemented with oil seed cakes. Food Chemistry, v.76, p.27-31, 2002.

SHASHIREKHA, M.N.; RAJARATHNAM, S.; BANO, Z. Effects of supplementing rice straw growth substrate with cotton seed on the analytical characteristics of the mushroom, Pleurotus florida (Block \& Tsao). Food Chemistry, v.92, n.2, p.255-259, 2005.

STURION, G.L.; OETTERER, M. Composição química de cogumelos comestíveis (Pleurotus spp.) originados de cultivos em diferentes substratos. Ciência e Tecnologia de Alimentos, v.15, p.189-193, 1995.

TORO, G.V.; VEJA, R.C.; GARIN-AGUILAR, M.E.; LARA, H.L. Biological quality of proteins from three strains of Pleurotus spp. Food Chemistry, v.94, n.4, p.494-497, 2006.

WANG, D.; SAKODA, A.; SUZUKI, M. Biological efficiency and nutritional value of Pleurotus ostreatus cultivated on spent beer grain. Bioresource Technology. v.78, p.293-300, 2001.

YILDIZ, A.; KARAKAPLAN, M.; AYDIN, F. Studies on Pleurotus ostreatus (Jacq. ex. fr.) Kum. var. salignus (Pers. ex Fr.) Konr. et Maubl.: cultivation, proximate composition, organic and mineral composition of carpophores. Food Chemistry, v.61, p.127-130, 1998.

ZADRAZIL, F; DUBE, H.C. The oyster mushroom. Importance and prospects. Mushroom Research, v.1, p.25-32, 1992.

Recebido em 13/2/07

Aceito em 20/11/08 